\title{
CORRELAÇÃO ENTRE TESTES DE VELOCIDADE E AGILIDADE
}

Eliton Marcio Zanoni, Josiane Aparecida de Jesus, Elisabeth Baretta, Rudy José Nodari Júnior

Universidade do Oeste de Santa Catarina - UNOESC.

Email: elitonatletismo@hotmail.com

Acesso DOI: http://dx.doi.org/10.34059/ciejop.2019v28i1-9

Introdução: A velocidade e a agilidade são citadas na literatura como componentes importantes da performance física. Em determinadas situações dos jogos, por exemplo, ser mais veloz acarreta chegar mais rápido na bola, ou antes do adversário e ser mais ágil implica em esquivar-se de impactos, deslocar-se frontalmente, lateralmente, ou seja, ser mais eficaz na resolução dos problemas enfrentados em jogos e ser mais potente, contribui para o sucesso do atleta em ambas as ações. $O$ objetivo da pesquisa foi comparar o teste de velocidade com o teste de agilidade para verificar sua correlação. Método: Fizeram parte da amostra 1.080 estudantes da rede municipal e estadual de Joaçaba, SC, de 8 a 19 anos do sexo masculino, com média e desvio padrão de idade de 12 anos $( \pm 2)$, peso de $47,6 \mathrm{~kg}( \pm 14,8)$ e estatura de $1,53 \mathrm{~m}( \pm 0,15)$ coletados entre os anos de 2011 e 2014. A avaliação dos testes de velocidade e agilidade foram o teste de sprint de $20 \mathrm{~m} / \mathrm{s}$ e o teste do quadrado respectivamente, realizados conforme o Manual do Proesp, proposto por Gaya e Gaya (2016). Para as análises estatísticas o teste de normalidade AndersonDarling test, que observou distribuição normal dos dados. Na sequência foi realizado correlação de Pearson estabelecendo como nível de significância $p \leq 0,05$. Resultados: Os resultados demonstram haver correlação quando comparados os testes de velocidade e agilidade $(p=0,0001)$, sendo esta correlação moderada $(r=0,65)$, ou seja, os participantes que tiveram bom desempenho em testes de agilidade, possivelmente obterão bom desempenho nos testes de sprint de $20 \mathrm{~m} / \mathrm{s}$. Conclusão: Se percebe correlação entre testes de velocidade e agilidade, predizendo que indivíduos que possuem velocidade em teste de sprint de $20 \mathrm{~m} / \mathrm{s}$, também devem ser muito ágeis, para acelerar muito rápido em curto espaço. Essa pode ser a resposta da correlação significativa dos testes realizados.

Palavras-chave: Avaliação, Velocidade, Agilidade 